\title{
Location Routing Problem with Consideration of CO2 Emissions Cost: A Case Study
}

\author{
Ananda Noor Sholichah *, Y Yuniaristanto, I Wayan Suletra \\ Industrial Engineering Department, Engineering Faculty, Universitas Sebelas Maret, Indonesia \\ Jl. Ir Sutami No.36 A, Pucangsawit, Jebres, Surakarta, Jawa Tengah, Indonesia \\ * Corresponding author: anandanosho@gmail.com
}

\section{ARTICLE INFO}

Article history

Received December 1, 2019

Revised August 20, 2020

Accepted August 22, 2020

Available Online August 30, 2020

Keywords

MILP

Location Routing Problem

Carbon Emissions

Time Windows

logistic

\begin{abstract}
Location and routing are the main critical problems investigated in a logistic. Location-Routing Problem (LRP) involves determining the location of facilities and vehicle routes to supply customer's demands. Determination of depots as distribution centers is one of the problems in LRP. In LRP, carbon emissions need to be considered because these problems cause global warming and climate change. In this paper, a new mathematical model for LRP considering $\mathrm{CO} 2$ emissions minimization is proposed. This study developed a new Mixed Integer Linear Programming (MILP) model for LRP with time windows and considered the environmental impacts. Finally, a case study was conducted in the province of Central Java, Indonesia. In this case study, there are three depot candidates. The study results indicated that using this method in existing conditions and constraints provides a more optimal solution than the company's actual route. A sensitivity analysis was also carried out in this case study.
\end{abstract}

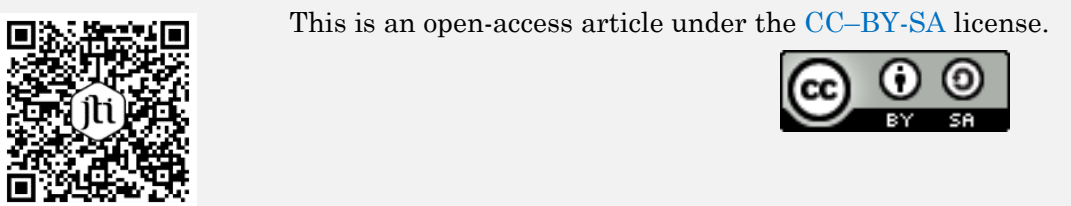

\section{Introduction}

Good coordination between depot locations and vehicle routes is one of the biggest challenges in supply chain management [1]. Determining the depot location or Facility Location Problem (FLP) and the distribution route or Vehicle Routing Problem (VRP) is solved separately. It produces more solutions than optimal [2]. One variation of FLP and VRP is the Location Routing Problem (LRP) [3]. LRP is the problem of determining the facility's location and vehicle routes to serve a certain number of customers to minimize location and route costs. The transportation costs can be reduced by cooperating between the two companies in delivering goods [4]. One form of cooperation is to use several joint depots as a distribution center. As urbanization still advances, environmental issues will become more important in urban areas [5]. The increasing flow of urban freight transportation harms the urban environment's quality, such as air pollution resulting from carbon dioxide emissions, noise, and congestion [6].

The transportation sector contributes to the second-largest source of $\mathrm{CO} 2$ emissions, which causes Climate Change [7]. The environmental effect of carbon emission 
is often ignored in manufacturer and transportation activity [8]. One of the measurements of environmental factors is based on $\mathrm{CO} 2$ emissions [9]. According to Kabashkin [10], although urban freight transportation only accounts for $10-18 \%$ of congestion, it contributes significantly to removing air pollution. The control of the environmental impacts is a considerable challenge to the daily operations of modern logistics companies. It is because of the increasing carbon dioxide emissions [11]. Reducing carbon emissions in logistics operations is essential because it is a carbon emission source [12]. The right route can reduce total costs, operating time, and $\mathrm{CO} 2$ emissions [13]. Besides, the time windows problem needs to be considered in the LRP problem because it can increase customer loyalty.

The researchers claim that the company's success depends on determining suitable location-allocation and distribution [14]. A few variations of LRP are investigated, and most of the early studies consider either capacitated depots and vehicles [15]. Since 2007, a few studies have addressed this issue with capacity limitations for the warehouses and the vehicles called the capacitated location-routing problem (CLRP). Belenguer [16] and Contardo [17] have proposed exact methods to solve the CLRP problem. Furthermore, distribution routes must consider the time window to increase customer satisfaction [18]. This issue is called the location-routing problem with time windows [19]. The variant with time windows has vehicles with limited capacity, and the specific delivery time windows were implemented by Zhang [20]. Wang [21] studied Two-echelon Location-Routing Routing with Time Windows (LRPTW) based on customer clustering to minimize costs and maximize customer satisfaction. The modification of facility location-allocation models by including inventory decisions is called the location-inventory problem, such as the one conducted by Diabat [22]. Green routing is a concept first introduced by Dukkanci [23]. It observes that cost is not usually directly proportional to the distance traveled and the vehicle's load.

There are a few previous research on location routing problems that consider the impact on the environment. The first study was carried out by Govindan [24]. A biobjective was proposed at two-echelon LRP with time constraints to improve food supply chain networks with manufacturing, distributions center, and retail. The purpose of the research was to minimize the total cost and impact on the environment. Another study was conducted by Koç [25]. He analyzed the impact of location, vehicle composition, and routes related to emissions on the city's transportation of goods. Then, Toro [26] studied the bi-objective green capacitated location-routing problem with two objective functions: minimizing operational costs and fuel consumption and $\mathrm{CO} 2$ emissions. Based on the previous studies, one way of reducing carbon emissions and fuel consumption is through improved routing decisions [27].

As mentioned earlier, Some studies have investigated LRP that consider the impact on the environment. However, none of the LRP studies considered CO2 emissions and time windows. This study aims to develop a mathematical model to solve the LRPTW problem to minimize total costs and $\mathrm{CO} 2$ emissions. The mathematical model is based on Mixed Integer Linear Programming (MILP). This research has contributed to developing the MILP model to solve LRP problems by considering time windows and considering the environmental impact to minimize the total distribution cost. This research is divided into several sections. Section 1 is the introduction outline. Section 2 is describing the proposed model and the research method. Section 3 is the results and discussion. Meanwhile, the conclusions and future work is presented in section 4 . 


\section{Methods}

\subsection{Assumptions, Notations, and Model Formulation}

The assumptions of the models comprise 1). The total shipment of goods may not exceed the capacity of the vehicle; 2). Homogeneous vehicle; 3). The demand of each customer is considered fixed each time shipment; 4). Rental costs for all depots are deemed to be the same; 5). Depot capacity is assumed to be the same; 6$)$. The vehicle speed is assumed fixed; 7). The unloading time at each store is expected to be the same, and 8). Emission factors are assumed fixed. Notations of parameters and decision variables:

M : The set of all potential depot locations

C : The set of all customers

$K_{m}$ : The set of all similar vehicles originating from the depot $\mathrm{m}$

$f_{m}$ : Set up fee for each depot at location $\mathrm{m}, \forall \mathrm{m} \in \mathrm{M}$

q : Vehicle capacity

$Q_{m}$ : Capacity of each depot $\mathrm{m}, \forall \mathrm{m} \in \mathrm{M}$

$O_{k}$ : Vehicle fee, $\forall \mathrm{k} \in \mathrm{K} \_\mathrm{m}$

$d_{i}$ : Customer request, $\forall \mathrm{i} \in \mathrm{C}$

$a_{i}$ : Minimum time to start serving customers i

$b_{i} \quad$ : Maximum time to start serving customers i

$E_{j} \quad$ : Emission factors

$C_{i j}$ : Operating costs between the depot and customers, $\forall(\mathrm{i}, \mathrm{j}) \in \mathrm{C}$

$t c_{p m}$ : Operating costs between the manufacture and depot $\forall \mathrm{m} \in \mathrm{M}$

$C_{m j}$ : Fixed costs on vehicles at the starting point, $\forall \mathrm{m} \in \mathrm{M}$ and $\forall \mathrm{j} \in \mathrm{C}$

$t_{i j}$ : Delivery time on track (i, j) and service time at I, $\forall(\mathrm{I}, \mathrm{j}) \in \mathrm{C}$

$y_{m}: 1$ if depot $\mathrm{m}$ is opened, and $\mathrm{O}$ otherwise

$X_{i j k}: 1$ if the track ( $\mathrm{i}, \mathrm{j}$ ) is used by vehicle $\mathrm{k}$, and 0 otherwise

$X_{m j k}: 1$ if vehicle $\mathrm{k}$ from depot $\mathrm{m}$ travels directly from depot $\mathrm{m} \mathrm{d}$ to $\mathrm{j}$, and 0 otherwise

$X_{\text {ink }}: 1$ if vehicle k travels from node $\mathrm{i}$ to $\mathrm{h}$, and 0 otherwise

$X_{h j k}: 1$ if vehicle $\mathrm{k}$ travels from node $\mathrm{h}$ to $\mathrm{j}$, and 0 otherwise

$W_{p m}: 1$ if the manufacture (p) is giving service to the depot $(\mathrm{m})$, and 0 otherwise

$U \quad$ : Number of vehicles

$S_{i k}:$ The time when the vehicle k delivered to customer i, $\forall(\mathrm{i}, \mathrm{j}) \in \mathrm{C}$

$\mathrm{m}$ : index of potential depot locations

$\mathrm{i} \quad$ : index of customer $\in \mathrm{C}$

$\mathrm{j} \quad$ : index of customer $\in \mathrm{C}$

The mathematical formulation for LRP is proposed in the Mixed Integer Linear Programming (MILP) model. The model is developed based on the research by Ponboon 2015 [28] in constraint (7)-(13) and Lerhlaly 2017 [29] in constraints (14)-(15).

The objectives function is shown below:

Minimize:

$\mathrm{Z}=\sum_{p \in P} \sum_{m \in M} t c_{p m} W_{p m}+\sum_{\mathrm{m} \in \mathrm{M}} \mathrm{f}_{\mathrm{m}} \mathrm{y}_{\mathrm{m}}+\sum_{\mathrm{m} \in \mathrm{M}} \sum_{\mathrm{j} \in \mathrm{A}} \sum_{\mathrm{k} \in \mathrm{K}} \mathrm{O}_{\mathrm{k}} \mathrm{x}_{\mathrm{mjk}}+\sum_{\mathrm{i} \in \mathrm{A}} \sum_{\mathrm{j} \in \mathrm{A}} \sum_{\mathrm{k} \in \mathrm{K}} \mathrm{C}_{\mathrm{ij}} \mathrm{x}_{\mathrm{ijk}}+\sum_{\mathrm{i} \in \mathrm{A}} \sum_{\mathrm{j} \in \mathrm{A}} \sum_{\mathrm{k} \in \mathrm{K}} \mathrm{C}_{\mathrm{ij}} \mathrm{E}_{\mathrm{j}} \mathrm{x}_{\mathrm{ijk}}$

Subject to: 


$$
\begin{aligned}
& \sum_{p \in P} W_{p m}=1 \\
& \sum_{m \in M} Y_{m} \leq m \\
& W_{p m} \leq \sum_{m \in M} Y_{m} \\
& \sum_{k \in K_{m}} \sum_{j \in V} x_{i j k}=1 \\
& \sum_{j \in V} x_{m j k}=1 \\
& \sum_{j \in V} x_{i m k}=1 \\
& \sum_{i \in V} x_{i h k}-\sum_{j \in V} x_{h j k}=0 \\
& \sum_{i \in C} d_{i} \sum_{j \in V} x_{i j k} \leq q \\
& \sum_{k \in K_{m}} \sum_{i \in C} d_{i} \sum_{j \in V} x_{i j k} \leq Q_{m} y_{m} \\
& \sum_{m \in M} \sum_{j \in A} \sum_{k \in K} x_{m j k}-U=0 \\
& s_{i k}+t_{i}+t_{i j}-M_{i j}\left(1-x_{i j k}\right) \leq s_{j k} \\
& a_{i} \leq S_{i k} \leq b_{i} \\
& y_{m} \in\{0,1\}, \\
& x_{i j k} \in\{0,1\}, \\
& s_{i k}>0
\end{aligned} \quad \forall(i, j) \in C
$$

Equation (1) is an objective function to minimize total costs, including CO2 emissions cost. Constraint (2) explains that each depot must be served. Constraint (3) ensures that the maximum number of depots that can be opened does not exceed the number of depots. Constraint (4) describes that manufacture $p$ gives service to just the opened depot. Constraint (5) shows each customer must be visited exactly once by vehicle $\mathrm{k}$. Constraint (6) and (7) explain that the vehicle starts shipping from depot m; it must return to the same depot. Constraint (8) ensures that the vehicle requires to leave customers $\mathrm{h}$ if visiting customers h. Constraint (9) is a guarantee to avoid vehicle capacity exceeding. Constraint (10) defines the capacity limits for each opened depot. Constraint (11) ensures that the shipment vehicle does not exceed the number of existing vehicles. Constraint (12)-(13) are time windows constraints. Decision variables are stated in constraints (14), (15), and (16).

\subsection{Data and Experimental Procedure}

The case study was conducted in the distribution areas of Solo, Sukoharjo, and Karanganyar areas in the province of Central Java, Indonesia. There were three depots (depot A, B, and C) candidates as the distribution centers. Determination of the location of the DC used Gravity Location Models. It assumed that both the stores and the manufactory could be placed as grid points on a plane. Distance between two points on the plane was calculated by the geometric distance [30]. Those models assumed that the distribution cost rose linearly with the amount shipped.

There were eight customers (from T1 to T8) whose demand must be fulfilled in this problem. The data used in this study are as follows: the capacity of vehicle was 1100 roll; 
Rental costs for all depots were 150,000,000 IDR/year; Depot capacity was 1500 roll; The vehicle speed was $30 \mathrm{~km} / \mathrm{hr}$; The unloading time at each store was 20 minutes; Emission factors was $1.018 \mathrm{Kg}$ CO2/km. Demand data can be seen in Table 1 . Table 2 is a matrix of the distance between depots and customers. Table 3 is the cost matrix obtained by multiplying the fuel cost per 1 kilometer by the distance between the two points. Table 4 is a matrix of the time required for a vehicle to travel once.

IBM ILOG CPLEX 12.8 was used to optimize the route in LRP, including a carbon emission cost problem, to minimize total distribution cost. Also, the sensitivity analysis is carried out to determine the effect of changes in fuel prices on the number of routes and the impact of changes in demand on the number of routes. Fuel and demand are essential parameters that need to be investigated in the LRP issues. In each sensitivity analysis, the study conducted experiments with six different scenarios. The demand parameter was increased by 100 or $4.5 \%$ in scenario $1,200,9 \%$ in scenario 2 , and 300 mats or $13.6 \%$ in scenario 3. Whereas in scenarios 4 and 5 , the demand was decreased by -100 mats or $4.5 \%$, -200 mats or $-9 \%$, and -300 mats or $-13.6 \%$.

Table 1 Demand data

\begin{tabular}{cc} 
Customer & Demand \\
\hline T1 & 277 \\
T2 & 286 \\
T3 & 270 \\
T4 & 277 \\
T5 & 286 \\
T6 & 270 \\
T7 & 267 \\
T8 & 267 \\
\hline
\end{tabular}

Table 2 Matrix of the distance between depots and customers $(\mathrm{Km})$

\begin{tabular}{cccccccccccc}
\hline & $\mathbf{A}$ & $\mathbf{B}$ & $\mathbf{C}$ & $\mathbf{1}$ & $\mathbf{2}$ & $\mathbf{3}$ & $\mathbf{4}$ & $\mathbf{5}$ & $\mathbf{6}$ & $\mathbf{7}$ & $\mathbf{8}$ \\
\hline $\mathbf{A}$ & 0.0 & 4.3 & 4.7 & 7.3 & 8.2 & 13.2 & 10.8 & 4.3 & 4.1 & 13.0 & 4.1 \\
$\mathbf{B}$ & 4.3 & 0.0 & 1.3 & 5.7 & 6.5 & 9.4 & 9.5 & 1.1 & 1.2 & 9.3 & 1.2 \\
$\mathbf{C}$ & 4.7 & 1.3 & 0.0 & 5.5 & 6.4 & 9.1 & 9.7 & 1.0 & 1.2 & 8.9 & 1.2 \\
$\mathbf{1}$ & 7.3 & 5.7 & 5.5 & 0.0 & 0.8 & 11.4 & 8.2 & 5.9 & 5.5 & 10.7 & 5.6 \\
$\mathbf{2}$ & 8.2 & 6.5 & 6.4 & 0.8 & 0.0 & 9.8 & 9.2 & 9.5 & 5.8 & 9.1 & 6.1 \\
$\mathbf{3}$ & 13.2 & 9.4 & 9.1 & 11.4 & 9.8 & 0.0 & 18.7 & 10.5 & 10.3 & 1.2 & 10.7 \\
$\mathbf{4}$ & 10.8 & 9.5 & 9.7 & 8.2 & 9.2 & 18.7 & 0.0 & 8.5 & 8.3 & 15.9 & 8.2 \\
$\mathbf{5}$ & 4.3 & 1.1 & 1.0 & 5.9 & 9.5 & 10.5 & 8.5 & 0.0 & 0.3 & 9.1 & 1.5 \\
$\mathbf{6}$ & 4.1 & 1.2 & 1.2 & 5.5 & 5.8 & 10.3 & 8.3 & 1.2 & 0.0 & 9.4 & 1 \\
$\mathbf{7}$ & 13.0 & 9.3 & 8.9 & 10.7 & 9.1 & 1.2 & 15.9 & 9.1 & 9.4 & 0.0 & 10.1 \\
$\mathbf{8}$ & 4.1 & 1.2 & 1.2 & 5.6 & 6.1 & 10.7 & 8.2 & 1.5 & 1 & 10.1 & 0.0 \\
\hline
\end{tabular}


Table 3 Operating Cost Matrix Between The Depot and Customers (IDR/Km)
A
B
C
2
3
4
5
6
7
8

\begin{tabular}{cccccccccccc}
\hline A & 0 & 19996 & 21856 & 33947 & 38132 & 61383 & 50223 & 19996 & 19066 & 60453 & 19066 \\
$\mathbf{B}$ & 19996 & 0 & 6045 & 26506 & 30227 & 43712 & 44177 & 5115 & 5580 & 43247 & 5580 \\
& & & & & & & & & & & \\
$\mathbf{C}$ & 21856 & 6045 & 0 & 25576 & 29762 & 42317 & 45107 & 4650 & 5580 & 41387 & 5580 \\
$\mathbf{1}$ & 33947 & 26506 & 25576 & 0 & 3720 & 53013 & 38132 & 27436 & 25576 & 49758 & 26041 \\
& & & & & & & & & & & \\
$\mathbf{2}$ & 38132 & 30227 & 29762 & 3720 & 0 & 45572 & 42782 & 44177 & 26971 & 42317 & 28367 \\
$\mathbf{3}$ & 61383 & 43712 & 42317 & 53013 & 45572 & 0 & 86960 & 48828 & 47898 & 5580 & 49758 \\
$\mathbf{4}$ & 50223 & 44177 & 45107 & 38132 & 42782 & 86960 & 0 & 39527 & 38597 & 73939 & 38132 \\
$\mathbf{5}$ & 19996 & 5115 & 4650 & 27436 & 44177 & 48828 & 39527 & 0 & 1395 & 42317 & 6975 \\
& & & & & & & & & & & \\
$\mathbf{6}$ & 19066 & 5580 & 5580 & 25576 & 26971 & 47898 & 38597 & 5580 & 0 & 43712 & 4650 \\
$\mathbf{7}$ & 60453 & 43247 & 41387 & 49758 & 42317 & 5580 & 73939 & 42317 & 43712 & 0 & 46967 \\
$\mathbf{8}$ & 19066 & 5580 & 5580 & 26041 & 28367 & 49758 & 38132 & 6975 & 4650 & 46967 & 0
\end{tabular}

Table 4 Time Matrix (Minute)

\begin{tabular}{cccccccccccc} 
& $\mathbf{A}$ & $\mathbf{B}$ & $\mathbf{C}$ & $\mathbf{1}$ & $\mathbf{2}$ & $\mathbf{3}$ & $\mathbf{4}$ & $\mathbf{5}$ & $\mathbf{6}$ & $\mathbf{7}$ & $\mathbf{8}$ \\
\hline $\mathbf{A}$ & 0.0 & 6.5 & 7.1 & 11.0 & 12.3 & 19.8 & 16.2 & 6.5 & 6.2 & 19.5 & 6.2 \\
$\mathbf{B}$ & 6.5 & 0.0 & 2.0 & 8.6 & 9.8 & 14.1 & 14.3 & 1.7 & 1.8 & 14.0 & 1.8 \\
$\mathbf{C}$ & 7.1 & 2.0 & 0.0 & 8.3 & 9.6 & 13.7 & 14.6 & 1.5 & 1.8 & 13.4 & 1.8 \\
$\mathbf{1}$ & 11.0 & 8.6 & 8.3 & 0.0 & 1.2 & 17.1 & 12.3 & 8.9 & 8.3 & 16.1 & 8.4 \\
$\mathbf{2}$ & 12.3 & 9.8 & 9.6 & 1.2 & 0.0 & 14.7 & 13.8 & 14.3 & 8.7 & 13.7 & 9.2 \\
$\mathbf{3}$ & 19.8 & 14.1 & 13.7 & 17.1 & 14.7 & 0.0 & 28.1 & 15.8 & 15.5 & 1.8 & 16.1 \\
$\mathbf{4}$ & 16.2 & 14.3 & 14.6 & 12.3 & 13.8 & 28.1 & 0.0 & 12.8 & 12.5 & 23.9 & 12.3 \\
$\mathbf{5}$ & 6.5 & 1.7 & 1.5 & 8.9 & 14.3 & 15.8 & 12.8 & 0.0 & 0.5 & 13.7 & 2.3 \\
$\mathbf{6}$ & 6.2 & 1.8 & 1.8 & 8.3 & 8.7 & 15.5 & 12.5 & 1.8 & 0.0 & 14.1 & 1.5 \\
$\mathbf{7}$ & 19.5 & 14.0 & 13.4 & 16.1 & 13.7 & 1.8 & 23.9 & 13.7 & 14.1 & 0.0 & 15.2 \\
$\mathbf{8}$ & 6.2 & 1.8 & 1.8 & 8.4 & 9.2 & 16.1 & 12.3 & 2.3 & 1.5 & 15.2 & 0.0
\end{tabular}

\section{Results and Discussion}

\subsection{Computational Results}

The optimization results using IBM ILOG CPLEX 12.8 showed that The optimal value in minimizing total distribution cost was 25,636,984 IDR. The cost component structure is as follows; the highest cost was obtained from the depot opening fee of 25,000,000 IDR. The vehicle cost was 231,554 IDR; CO2 emission expenditure cost was 208,765 IDR; distribution costs from the depot to customers was 177,172 IDR, and the factory to the depot cost was 47,897 IDR.

The computation results showed that the optimal solution produced two routes (route 1 and route 2). Two depots selected, namely depot B and C. Routes solution in the LRP problem, are shown in Fig. 1. On route 1, shipments started from Depot B - T6 - T4 - 
T8 - T5 and returned to Depot B. This route started from depot C at 08.00, then went to $\mathrm{T} 6$ at 09.40 , then to $\mathrm{T} 4$ at 10.33 to $\mathrm{T} 8$ at 11.05 , then to $\mathrm{T} 5$ at 11.28 , and returned to Depot $\mathrm{B}$ at 11.38 . On route 2, shipments started from Depot C - T3 - T7 - T2 - T1 and returned to Depot C. This route started from Depot C at 12.30 , then to T3 at 12.49 , then to T7 at 13.30, then to T2 at 14.04 then to T1 at 14.25 and returned to the Depot $\mathrm{C}$ at 15.00 .

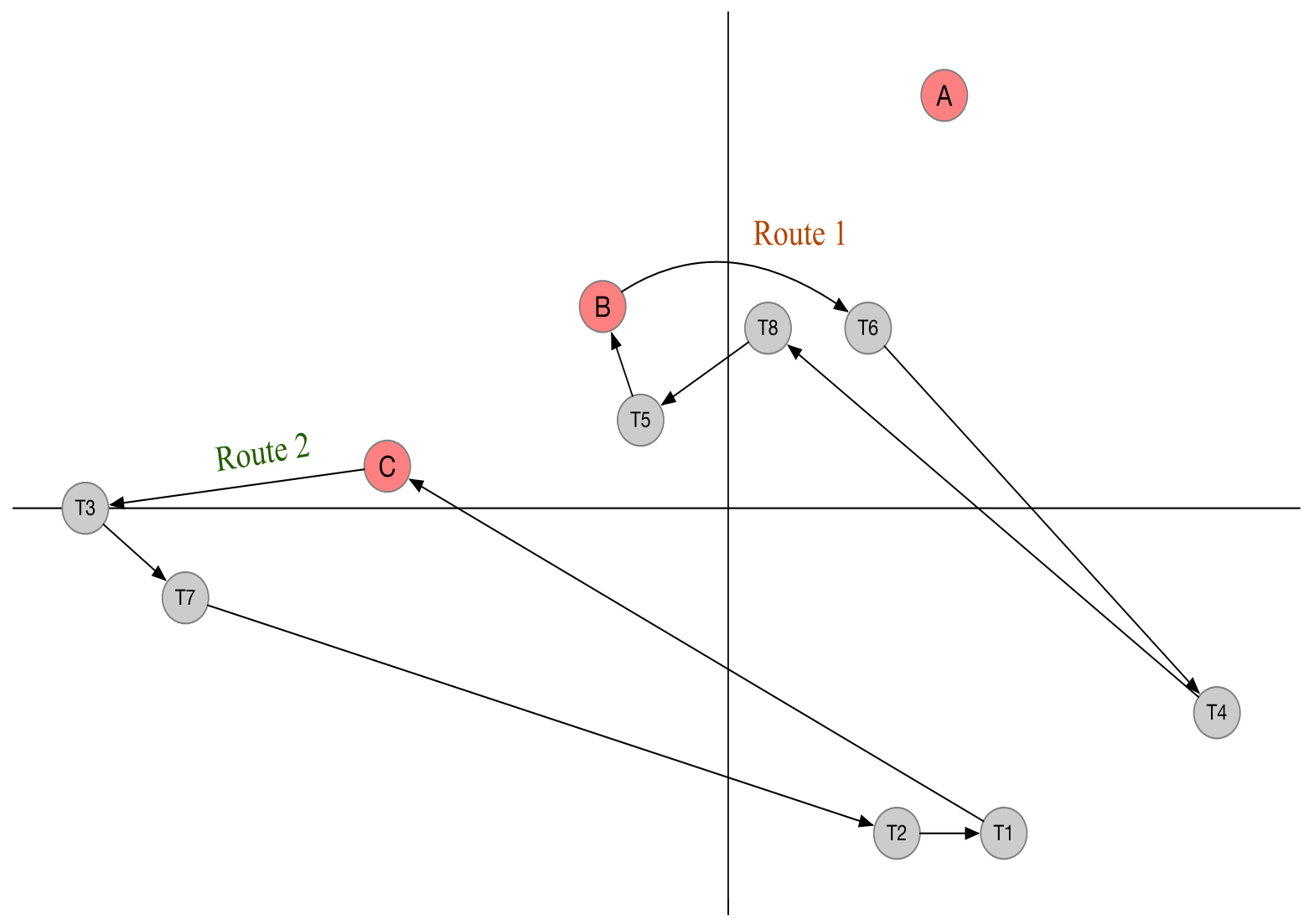

Fig. 1 Routes solution in LRP problem

\subsection{Sensitivity Analysis}

The effects of changes in fuel cost toward several routes can be seen in Fig. 2. It shows that if the cost is increased or reduced, so route decisions also change. Therefore, it can be concluded that the model is sensitive to the increase or decrease in fuel costs. In other words, the cost of fuel influence the number on the route in the LRP problem. Moreover, the effects of changes in demand toward the routes can be seen in Fig. 3 . When the demand parameter is increased by 100 or $4.5 \%$ in scenario 1,200 , or $9 \%$ in scenario 2 , and 300 or $13.6 \%$ in scenario 3 , the resulting route decision is different from the initial route decision. It is because the vehicle capacity also determines the route solution. Furthermore, if the demand is increased, it will require more than one vehicle; it causes the shipping route to change. In scenarios 4 and 5, namely when the demand is lowered by -100 or $-4.5 \%,-200$ or $-9 \%$, and -300 or $-13.6 \%$, the route decisions are the same as those of the initial route. 


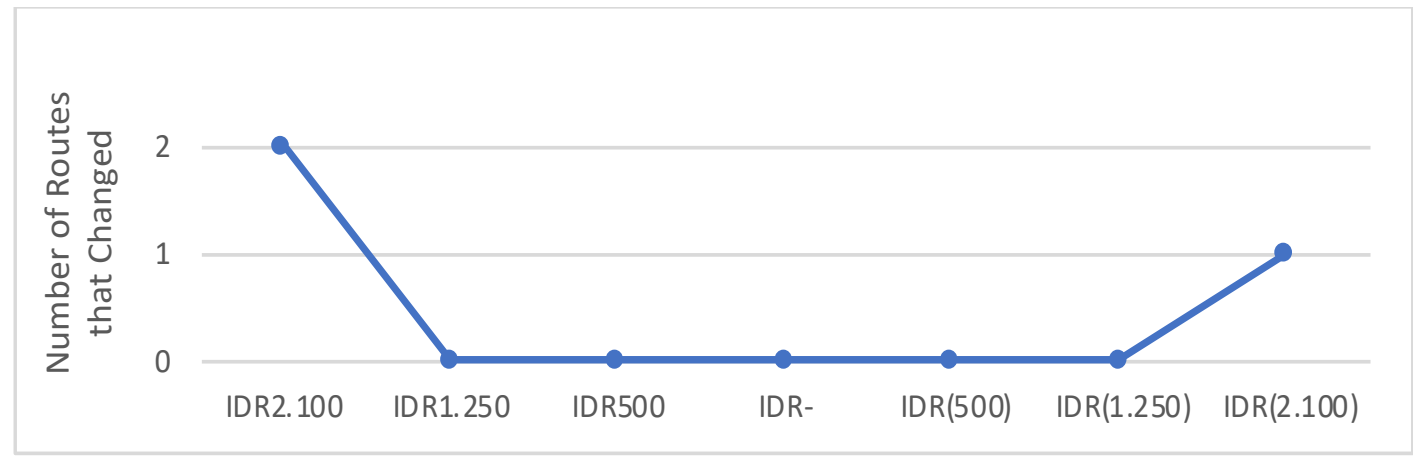

Fig. 2 Effects of Changes in the cost of fuels cost toward Routes

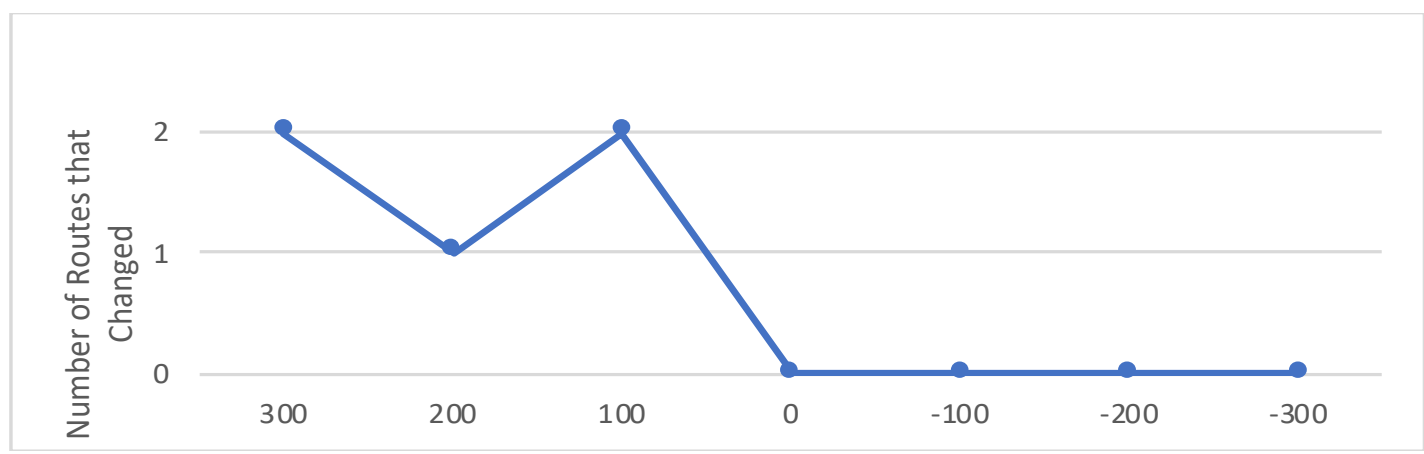

Fig. 3 Effects of Changes in Demand toward Routes

\section{Conclusion}

This research aims to develop a mathematical model to solve the LRPTW problem to minimize total costs and CO2 emissions. The researchers developed LRPTW that considered $\mathrm{C} 02$ emissions. Thus, Mixed Integer Linear Programming (MILP) was proposed to solve LRPTW acknowledging $\mathrm{C} 02$ emissions. This model was solved using ILOG IBM CPLEX 12.8. It concluded that the model could produce a better route based on the time windows, $\mathrm{CO} 2$ emissions, and the chosen depots. The suggestion For further research is to integrate the model with the delivery schedule and compare the solutions with popular heuristic and metaheuristic algorithms.

\section{Acknowledgments}

This research is supported by Institute for Research and Community Service, Universitas Sebelas Maret with Grant Penelitian Unggulan Terapan UNS (PUT-UNS) Research Program (Contract No. 516/UN27.21/PP/2019).

\section{References}

[1] C. Duhamel, P. Lacomme, C. Prins, and C. Prodhon, "A GRASP $\times$ ELS approach for the capacitated location-routing problem," Computers \& Operations Research, vol. 37, pp. 1912-1923, 2010. https://dx.doi.org/10.1016/j.cor.2009.07.004.

[2] S. Barreto, C. Ferreira, J. Paixão, and B. S. Santos, "Using clustering analysis in a capacitated location-routing problem," European Journal of Operational Research, vol. 179, pp. 968-977, 2007. https://dx.doi.org/10.1016/j.ejor.2005.06.074.

[3] C. Chen, R. Qiu, and X. Hu, "The Location-Routing Problem with Full Truckloads in Low-Carbon Supply Chain Network Designing," Mathematical Problems in Engineering, vol. 2018, p. 6315631, 2018. https://dx.doi.org/10.1155/2018/6315631. 
[4] J. R. Montoya-Torres, A. Muñoz-Villamizar, and C. A. Vega-Mejía, "On the impact of collaborative strategies for goods delivery in city logistics," Production Planning $\begin{array}{lllll}\& & \text { Control, } & \text { vol. } & 27, & \text { pp. }\end{array}$ https://dx.doi.org/10.1080/09537287.2016.1147092.

[5] M. Behnke and T. Kirschstein, "The impact of path selection on GHG emissions in city logistics," Transportation Research Part E: Logistics and Transportation Review, vol. 106, pp. 320-336, 2017. https://dx.doi.org/10.1016/j.tre.2017.08.011.

[6] K. Kijewska and M. Jedliński, "The Concept of Urban Freight Transport Projects Durability and Its Assessment within the Framework of a Freight Quality Partnership," Sustainability, vol. 10, p. 2226, 2018. https://dx.doi.org/10.3390/su10072226.

[7] R. Wei and C. Liu, "Research on carbon emission reduction in road freight transportation sector based on regulation-compliant route optimization model and case study," Sustainable Computing: Informatics and Systems, vol. 28, p. 100408, 2020. https://dx.doi.org/10.1016/j.suscom.2020.100408.

[8] M. F. Ibrahim and M. M. Putri, "Integrated Green Supply Chain Model to Reduce Carbon Emission with Permissible Delay-in-Payment Consideration," 2019, vol. 20, p. 12, 2019. https://dx.doi.org/10.22219/JTIUMM.Vol20.No2.128-139.

[9] H. Ouhader and M. El Kyal, "Combining Facility Location and Routing Decisions in Sustainable Urban Freight Distribution under Horizontal Collaboration: How Can Shippers Be Benefited?," Mathematical Problems in Engineering, vol. 2017, p. 8687515, 2017. https://dx.doi.org/10.1155/2017/8687515.

[10] E. Nathanail, "A Multistakeholders Multicriteria Decision Support Platform for Assessing Urban Freight Transport Measures," Cham, 2018, pp. 17-31. https://dx.doi.org/10.1007/978-3-319-74454-4_2.

[11] Y. Wang, K. Assogba, J. Fan, M. Xu, Y. Liu, and H. Wang, "Multi-depot green vehicle routing problem with shared transportation resource: Integration of timedependent speed and piecewise penalty cost," Journal of Cleaner Production, vol. 232, pp. 12-29, 2019. https://dx.doi.org/10.1016/j.jclepro.2019.05.344.

[12] X. Wang and X. Li, "Carbon reduction in the location routing problem with heterogeneous fleet, simultaneous pickup-delivery and time windows," Procedia Computer Science, vol. 112, pp. 1131-1140, 2017. https://dx.doi.org/10.1016/j.procs.2017.08.147.

[13] E. Taniguchi, City logistics : network modelling and intelligent transport systems. Bingley: Emerald, 2008.

[14] R. B. Lopes, S. Barreto, C. Ferreira, and B. S. Santos, "A decision-support tool for a capacitated location-routing problem," Decision Support Systems, vol. 46, pp. 366375, 2008. https://dx.doi.org/10.1016/j.dss.2008.07.007.

[15] M. Bagheri Hosseini, F. Dehghanian, and M. Salari, "Selective capacitated location-routing problem with incentive-dependent returns in designing used products collection network," European Journal of Operational Research, vol. 272, pp. 655-673, 2019. https://dx.doi.org/10.1016/j.ejor.2018.06.038.

[16] J.-M. Belenguer, E. Benavent, C. Prins, C. Prodhon, and R. Wolfler Calvo, "A Branch-and-Cut method for the Capacitated Location-Routing Problem," Computers \& Operations Research, vol. 38, pp. 931-941, 2011. https://dx.doi.org/10.1016/j.cor.2010.09.019.

[17] C. Contardo, J.-F. Cordeau, and B. Gendron, "A computational comparison of flow formulations for the capacitated location-routing problem," Discrete Optimization, vol. 10, pp. 263-295, 2013. https://dx.doi.org/10.1016/j.disopt.2013.07.005. 
[18] A. Expósito, J. Brito, J. A. Moreno, and C. Expósito-Izquierdo, "Quality of service objectives for vehicle routing problem with time windows," Applied Soft Computing, vol. 84, p. 105707, 2019. https://dx.doi.org/10.1016/j.asoc.2019.105707.

[19] M. S. Farham, H. Süral, and C. Iyigun, "A column generation approach for the location-routing problem with time windows," Computers \& Operations Research, vol. 90, pp. 249-263, 2018. https://dx.doi.org/10.1016/j.cor.2017.09.010.

[20] W. Zhang, D. Yang, G. Zhang, and M. Gen, "Hybrid multiobjective evolutionary algorithm with fast sampling strategy-based global search and route sequence difference-based local search for VRPTW," Expert Systems with Applications, vol. 145, p. 113151, 2020. https://dx.doi.org/10.1016/j.eswa.2019.113151.

[21] Y. Wang, K. Assogba, Y. Liu, X. Ma, M. Xu, and Y. Wang, "Two-echelon locationrouting optimization with time windows based on customer clustering," Expert Systems with Applications, vol. 104, pp. 244-260, 2018. https://dx.doi.org/10.1016/j.eswa.2018.03.018.

[22] A. Diabat and E. Theodorou, "A location-inventory supply chain problem: Reformulation and piecewise linearization," Computers \& Industrial Engineering, vol. 90, pp. 381-389, 2015. https://dx.doi.org/10.1016/j.cie.2015.05.021.

[23] O. Dukkanci, B. Y. Kara, and T. Bektaş, "The green location-routing problem," Computers \& Operations Research, vol. 105, pp. 187-202, 2019. https://dx.doi.org/10.1016/j.cor.2019.01.011.

[24] K. Govindan, A. Jafarian, R. Khodaverdi, and K. Devika, "Two-echelon multiplevehicle location-routing problem with time windows for optimization of sustainable supply chain network of perishable food," International Journal of Production Economics, vol. 152, pp. 9-28, 2014. https://dx.doi.org/10.1016/j.ijpe.2013.12.028.

[25] Ç. Koç, "A unified-adaptive large neighborhood search metaheuristic for periodic location-routing problems," Transportation Research Part C: Emerging $\begin{array}{lllll}\text { Technologies, } & \text { vol. } & 68, & \text { pp. } & 265-284,\end{array}$ https://dx.doi.org/10.1016/j.trc.2016.04.013.

[26] E. M. Toro, J. F. Franco, M. G. Echeverri, and F. G. Guimarães, "A multi-objective model for the green capacitated location-routing problem considering environmental impact," Computers \& Industrial Engineering, vol. 110, pp. 114-125, 2017. https://dx.doi.org/10.1016/j.cie.2017.05.013.

[27] K. Chaudhary and P. Vrat, "Optimal location of precious metal extraction facility (PMEF) for E-waste recycling units in National Capital Region (NCR) of India," OPSEARCH, vol. 54, pp. 441-459, 2017. https://dx.doi.org/10.1007/s12597-0160287-0.

[28] S. Ponboon, A. G. Qureshi, and E. Taniguchi, "Evaluation of Cost Structure and Impact of Parameters in Location-routing Problem with Time Windows," Transportation Research Procedia, vol. 12, pp. 213-226, 2016. https://dx.doi.org/10.1016/j.trpro.2016.02.060.

[29] S. Lerhlaly, M. Lebbar, H. Allaoui, S. Afifi, and D. Ouazar, "An inventory location routing model with environmental considerations," MATEC Web Conf., vol. 105, p. 00002, 2017. https://dx.doi.org/10.1051/matecconf/201710500002.

[30] M. Turkensteen, "The accuracy of carbon emission and fuel consumption computations in green vehicle routing," European Journal of Operational Research, vol. 262, pp. 647-659, 2017. https://dx.doi.org/10.1016/j.ejor.2017.04.005. 